\title{
Reflexões sobre políticas de livro e leitura de secretarias municipais de educação do Estado do Rio de Janeiro
}

Patrícia Corsino ${ }^{1}$

Rafaela Vilela ${ }^{2}$

Sônia Travassos ${ }^{3}$

De modo algum a aquisição de livros se resolve apenas com dinheiro ou apenas com o conhecimento de perito. Nem mesmo este dois fatores juntos bastam para o estabelecimento de uma verdadeira biblioteca, que sempre contém, ao mesmo tempo, o inescrutável e o inconfundível.

Walter Benjamin

Walter Benjamin, ao desempacotar sua biblioteca, tece várias considerações sobre a relação entre o colecionador e seus pertences. $\mathrm{Na}$ desordem de caixotes abertos, o autor traz as lembranças que cada livro, folheto ou álbum despertam. Chama a atenção para a desordem habitual dos livros que compõem uma biblioteca. Por ser um lugar aberto ao acaso e ao destino de cada novo elemento que entra na coleção, impõe ao colecionador uma tensão dialética entre a ordem e a desordem: "toda ordem é precisamente uma situação oscilante à beira do precipício" (Benjamin, 1994, p. 228). Constituir uma biblioteca é justamente estar diante de algo ao mesmo tempo inescrutável, impenetrável e incompreensível, mas também inconfundível, porque cada uma tem suas próprias características, já que são marcadas pelas diferentes ordens dadas pelos sujeitos que ali estabelecem relações. Uma "verdadeira biblioteca" seria, então, aquela que guarda e desperta memórias individuais e coletivas, que permite o penetrar e as descobertas, mas, simultaneamente, esconde e guarda mistérios a serem desvendados.

\footnotetext{
${ }^{1}$ Doutora em educação e professora da Universidade Federal do Rio de Janeiro (UFRJ), Rio de Janeiro, RJ, Brasil. E-mail: corsinopat@gmail.com

${ }^{2}$ Doutoranda em educação pela Universidade Federal do Rio de Janeiro (UFRJ), Rio de Janeiro, RJ, Brasil. E-mail: rafalouise@gmail.com

${ }^{3}$ Doutoranda em educação pela Universidade Federal do Rio de Janeiro (UFRJ), Rio de Janeiro, RJ, Brasil. E-mail: soniamariatravassos@gmail.com
} 
Nesta perspectiva, perguntamos: como pensar as bibliotecas escolares a partir das reflexões benjaminianas?

Este artigo se propõe a analisar questões referentes à composição de acervos e à organização de bibliotecas de escolas das redes municipais de ensino de municípios do Estado do Rio de Janeiro. As análises apresentadas fazem parte dos resultados da pesquisa "Infância, Linguagem e Escola: a Leitura Literária em Questão", desenvolvida no Programa de PósGraduação em Educação da Universidade Federal do Rio de Janeiro. A pesquisa tem como objetivo geral conhecer e analisar políticas de livro e leitura desenvolvidas pelas secretarias municipais de educação dos municípios do Estado do Rio de Janeiro e suas implicações em práticas de leitura literária de creches, pré-escolas e escolas de ensino fundamental. Para a concretização deste objetivo, a pesquisa se organiza em três eixos de estudo: i) acervos; ii) espaços de livro e leitura; e iii) mediações ou apropriações. Na perspectiva das implicações e apropriações, vem desenvolvendo estudos qualitativos em turmas de educação infantil e anos iniciais do ensino fundamental de escolas públicas, de modo a abordar as questões pertinentes a cada eixo e conhecer e analisar o lugar que a literatura ocupa na formação de crianças e professores. Na perspectiva das políticas, elaborou um questionário, com questões abertas e fechadas, que foi distribuído a 92 secretarias municipais de educação do Estado do Rio de Janeiro e respondido por $62(67 \%)$ por meio dos responsáveis por programas e projetos de livro e leitura.

Cabe ressaltar que esse movimento simultâneo e circular da pesquisa, de trânsito entre o micro e o macro e vice-versa, tem favorecido pensar o mesmo tema de estudo a partir de pontos de vista que se completam. O questionário teve a função de traçar tendências, conhecer movimentos ensaiados pelas políticas de livro e leitura das secretarias municipais do Estado do Rio de Janeiro. As questões elaboradas emergiram dos estudos qualitativos, o que deu ao questionário uma extensão de 36 perguntas. As indagações às agendas das políticas educacionais municipais giraram em torno de conhecer, analisar e entender programas, projetos e ações relativos ao livro e à promoção da leitura desenvolvidos pelas secretarias em creches, pré-escolas e escolas dos anos iniciais do Ensino Fundamental. Foi nosso objetivo destacar as ações em creches e pré-escolas para analisar como estão sendo inseridas nos programas destinados à educação básica das redes públicas municipais. O retorno do questionário exigiu muitas investidas dos componentes do grupo de pesquisa, mas foi possível obter respostas de 
municípios de todas as regiões do Estado, abarcando a diversidade não apenas geográfica, mas econômica e populacional (cerca de $80 \%$ da população do estado, visto que, dos 21 municípios que compõem a Região Metropolitana, apenas três não responderam ao questionário). Neste sentido, entendemos que as análises apresentadas têm abrangência e representatividade no Estado do Rio de Janeiro.

Este artigo analisa respostas a perguntas do questionário que versam sobre os acervos e espaços de livro e leitura. Para sustentar as análises sobre livro e leitura, buscou-se interlocução com Chartier (1994), Britto (2011), Corsino (2010) e Paiva (2012). As considerações sobre biblioteca ancoraram-se nos estudos de Campello (2010), Mollo e Nobrega (2010) e Perrotti (2004).

Como são constituídos os acervos das bibliotecas escolares dos municípios do Estado do Rio de Janeiro? Que gêneros e suportes de leitura vêm sendo priorizados para compras? Onde são guardados os acervos? Como eles são catalogados e organizados no espaço da biblioteca? Os espaços destinados à biblioteca são também compostos por outros acervos, além de livros? Nesse caso, como os espaços se organizam e se flexibilizam para incorporá-los? Na busca de resposta a estas questões, o texto foi organizado em cinco partes: i) apresenta considerações sobre como as secretarias municipais de educação compõem os acervos das creches, pré-escolas e escolas dos anos iniciais do ensino fundamental; ii) aborda os lugares onde ficam organizados os livros literários nas escolas; iii) tece apontamentos sobre os critérios de classificação e organização dos acervos; iv) discute a biblioteca ou sala de leitura nas escolas como lugar de interlocução; e v) finaliza apresentando um panorama dos achados da pesquisa.

\section{Composição dos acervos}

A composição dos acervos das escolas brasileiras, desde 1997, conta com obras distribuídas pelo Governo Federal no âmbito do Programa Nacional Biblioteca da Escola (PNBE). Desde 2012, o programa passou a atender a todos os segmentos da educação básica, da creche à educação de jovens e adultos. Segundo Paiva (2012), a seleção das obras do programa tem como objetivo contemplar a diversidade de gêneros literários a partir de critérios que considerem a qualidade textual, temática e gráfica. Para a autora, a continuidade do PNBE evidencia uma valorização das bibliotecas escolares 
das escolas públicas "como um espaço promotor da universalização do conhecimento e, também, da universalização do acesso a acervos pelo coletivo da escola" (Paiva, 2012, p. 16).

Partindo do pressuposto de que o PNBE já estava fazendo a distribuição de livros de qualidade para composição dos acervos das bibliotecas escolares, a intenção foi conhecer, além dos livros que já são distribuídos pelo Governo Federal, como são compostos os acervos em creches, pré-escolas e escolas dos anos iniciais do Ensino Fundamental no Estado do Rio de Janeiro. O objetivo foi entender as ações das secretarias municipais de educação em prol de uma ampliação do acesso ao livro e à leitura pelo coletivo da escola. Os respondentes do questionário tinham a opção de assinalar mais de uma opção sobre as práticas de composição de acervos. O gráfico 1, a seguir, apresenta como é feita esta composição.

GRÁFICO 1 - Modos de composição de acervos de bibliotecas de escolas públicas municipais, por segmento - Estado do Rio de Janeiro (2015)

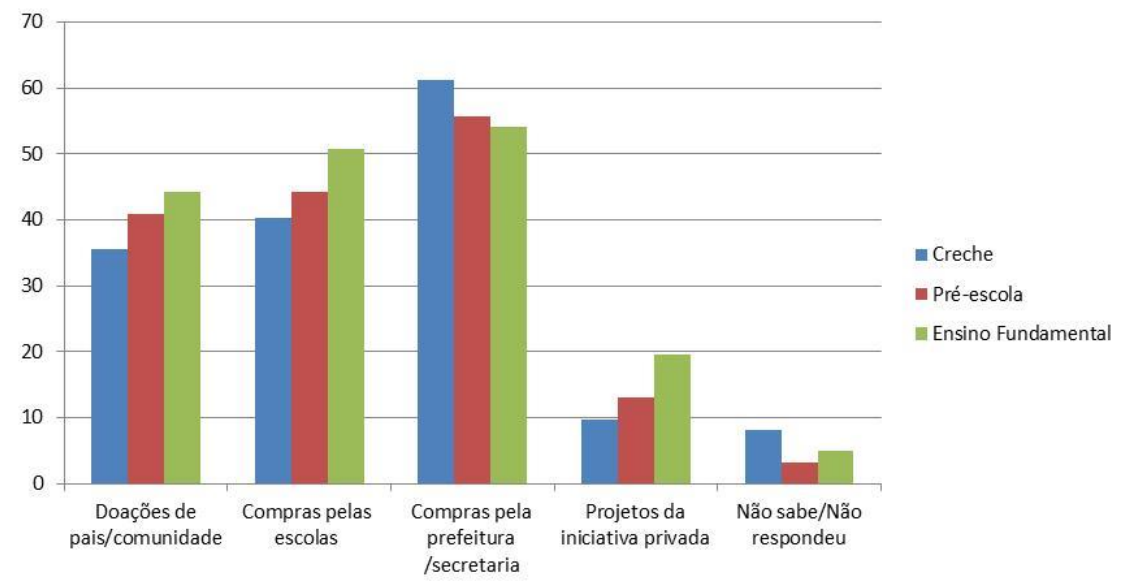

Fonte: Microdados da pesquisa "Infância, Linguagem e Escola: a Leitura Literária em Questão". Rio de Janeiro: UFRJ, 2015.

A resposta mais assinalada nos três segmentos mostra que os acervos são compostos em sua maioria a partir de compras realizadas pela prefeitura ou pela secretaria de educação - creches $(61,29 \%)$, pré-escolas $(55,74 \%)$, ensino fundamental $(54,10 \%)$ - seguidas de compras realizadas com verbas disponibilizadas às escolas pelas prefeituras ou secretarias creches $(40,32 \%)$, pré-escolas $(44,26 \%)$, ensino fundamental $(50,82 \%)$. 
Próximo às duas primeiras opções, a terceira resposta mais assinalada refere-se à aquisição de acervos por via de doações de pais e da comunidade em geral - creches $(35,48 \%)$, pré-escolas $(40,98 \%)$, ensino fundamental $(44,26 \%)$. A opção menos assinalada em relação aos três segmentos foi a que se refere à aquisição de acervos via projetos em parceria com a iniciativa privada - creches $(9,68 \%)$, pré-escolas $(13,11 \%)$ e ensino fundamental (19,67\%). Ao observar e comparar estas respostas, é possível notar a importância das verbas públicas para a aquisição de acervos dos municípios respondentes (seja consolidada diretamente pela prefeitura ou secretaria, seja repassada para as escolas). Os dados indicam que creches e pré-escolas estão sendo mais contempladas com compras centralizadas pela secretaria do que com compras realizadas pelas escolas. Também chama a atenção as respostas sobre as parcerias com a iniciativa privada para a aquisição de acervos. Percebe-se um investimento maior em projetos que têm o ensino fundamental como segmento a ser atingido, mas as parcerias não chegam a $20 \%$ das respostas, o que reitera o importante lugar das compras realizadas pela esfera pública e a responsabilidade das secretarias e dos professores nas escolhas dos acervos. As diferenças de investimento na composição de acervos entre os segmentos educação infantil e ensino fundamental apresentam poucas variações. $O$ que traz indagações sobre as diferentes concepções de leitura e lugares que ela ocupa no percurso escolar dos estudantes. O significativo percentual de compras para a educação infantil indica uma tendência a se pensar a leitura neste segmento em sua dimensão partilhada, ou seja, os livros são comprados para serem lidos pelos professores com e para as crianças. Uma visão de que a formação do leitor se inicia muito antes de uma leitura stricto sensu e autônoma, o que vem ao encontro das reflexões travadas no âmbito dos estudos qualitativos da pesquisa institucional na qual o questionário se insere.

Ainda no que se refere à composição e à aquisição de acervos, foi formulada uma pergunta a respeito dos gêneros e suportes de leitura priorizados para compras pelas prefeituras ou secretarias, devendo a resposta ser colocada em ordem de importância, de 1 a 10 . O gráfico 2, a seguir, indica o que tem sido priorizado nas compras. 
GRÁFICO 2 - Tipos de acervos priorizados pelas secretarias municipais de educação para compra e distribuição nas escolas públicas municipais - Rio de Janeiro (2015)

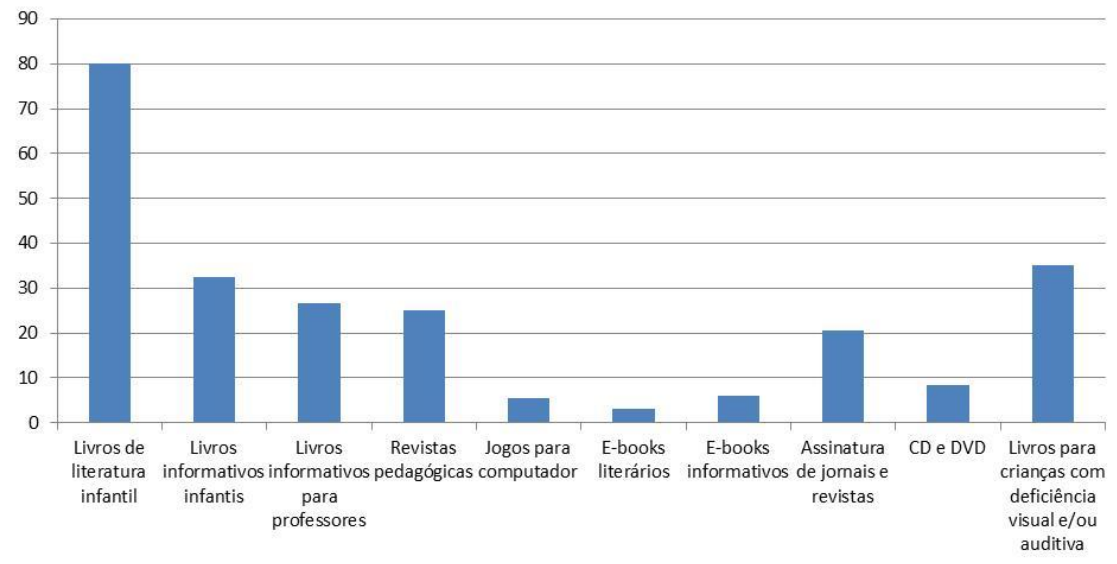

Fonte: Microdados da pesquisa "Infância, Linguagem e Escola: a Leitura Literária em Questão". Rio de Janeiro: UFRJ, 2015.

As respostas revelaram que os municípios elegem mais de uma opção como mais importante. Assim, o gênero assinalado mais vezes em primeiro lugar pelos respondentes foi o que se refere à opção dos "livros de literatura infantil" (80\%). A opção "livros informativos infantis" também aparece como o mais importante para 32,56\% dos municípios. Por sua vez, $26,67 \%$ dos respondentes marcaram a opção "livros informativos para a formação de professores" como a mais importante, e em número bem semelhante aparece a opção em relação à compra de "revistas pedagógicas", com 25\% dos respondentes. Vale destacar as opções relacionadas a suportes como "Jogos e programas para computador", "Ebooks literários", "E-books informativos" e "CD e DVD": estes foram pouco escolhidos como primeira opção em importância, atingindo um número de respostas menor que $8 \%$. Outro destaque é o que se refere à aquisição de livros ou materiais para crianças portadoras de deficiência visual e/ou auditiva, sendo essa alternativa marcada como opção mais importante para 35\% dos respondentes, revelando uma tendência nas secretarias municipais de educação em se equipar com materiais que possam desenvolver uma educação inclusiva. A partir destas respostas, o que seria possível inferir em relação às escolhas de gêneros e suportes dos 
acervos que compõem as salas de leitura e bibliotecas das escolas públicas municipais do Estado do Rio de Janeiro?

A biblioteca é um espaço que comporta diferentes tipos de leituras e estas se apresentam cada vez mais em suportes que vão além dos impressos. Segundo Britto (2011, p. 23), as modernas bibliotecas “dispõem de textos em outros meios e outros recursos de estudo - a cibercultura. Aliás, bibliotecas estão já inteiramente no hiperespaço da web". Para o autor, as bibliotecas podem ter "caras e jeitos" diferentes e cada uma se organizará de acordo com suas necessidades de estudo, de produção, de lazer, de vivência do público. As bibliotecas escolares exercem funções que variam conforme os projetos políticos pedagógicos das escolas onde se localizam, podendo ocupar um lugar central ou mais periférico nos projetos, com ações mais restritas ou mais ampliadas interna e externamente. Como se articulam às propostas, condições e necessidades da comunidade escolar, apresentam diversas formas de organização e dinamização de seus acervos. Mas elas também comportam diferentes tipos de leitura e podem exercer uma importante função de democratização do acesso aos bens culturais às crianças e adultos que nelas circulam. Assim, cada biblioteca escolar se configura entre a ordem e a desordem de livros literários, livros informativos, revistas, jornais, CD, DVD, entre outros acervos, e também de mesas, cadeiras, estantes, almofadas, televisão, computadores onde podem ser acessados inúmeras textos: livros digitais, sites informativos etc. Sua materialidade é desencadeadora de diferentes ações educativas e culturais. As respostas do questionário evidenciaram a prioridade das secretarias de educação na aquisição de acervos para as escolas públicas em suportes impressos, principalmente nos gêneros "livros de literatura infantil", "livros informativos infantis" e "livros informativos para a formação de professores", ou seja, o livro se destaca como objeto das bibliotecas escolares, confirmando o importante valor simbólico que ele ocupa nas escolas.

Para Chartier (1996), ao logo da história do mundo ocidental, foi criada a legibilidade de uma cultura textual que liga o próprio conceito de texto a uma forma particular de livro: o códex - composto por cadernos, formados por folhas e páginas e protegido por uma encadernação. Esta legibilidade tem uma ordem própria, pensada e construída em relação a uma modalidade de produção, de conservação e de comunicação do escrito. Para o autor, as mudanças nos meios de comunicação e recepção da escrita precisam ser acompanhadas com reflexões históricas, jurídicas e 
filosóficas, pois "o universo de textos eletrônicos significará, necessariamente, um distanciamento em relação às representações mentais e às operações intelectuais especificamente ligadas às formas que teve o livro no Ocidente há dezessete ou dezoito séculos" (1996, p. 106). Há mudanças em curso quando se passa do códex à tela que não se limitam a uma mera mudança de suporte e implicam em uma série de redefinições do escrito nas sociedades contemporâneas. Neste ponto é ainda Chartier (1996, p. 107) que nos interroga sobre o que seria então a biblioteca do futuro. Para ele deverá ser também "um lugar onde poderão ser mantidos o conhecimento e a compreensão da cultura escrita nas formas que foram, e ainda hoje são, majoritariamente as suas". E acrescenta: "apenas preservando a inteligência da cultura do códex poderemos gozar a 'felicidade extravagante' prometida pela tela" (Chartier, 1996, p. 107). Esta perspectiva se articula ao que Benjamin anuncia na epígrafe deste artigo, há um importante espaço na/da biblioteca que se relaciona à memória individual - pela experiência de leitura de cada um - e coletiva, no sentido dado por Chartier, que seria a própria materialidade do impresso, nas formas que o constituíram.

Ainda que possamos acessar obras e informações por meio digital, as respostas ao questionário confirmaram a valorização da materialidade do livro nas bibliotecas escolares. Materialidade que determina leituras que incluem as dimensões visual, tátil e olfativa, além de uma portabilidade de certa forma simples: o livro se deixa carregar, embalar, segurar, folhear, avançar e recuar, ver o todo e as partes simultaneamente, ir e vir com ele para diferentes lugares, voltar a ele sempre que sentir vontade e tantas outras ações que, desde bem pequenas, as crianças aprendem e se apropriam. As respostas mostraram também que secretarias municipais de educação priorizam a compra de livros literários e livros informativos para a educação infantil e anos iniciais do ensino fundamental. Dois gêneros distintos com propostas interlocutivas diversas e que demandam do leitor diferentes modos de ler.

Mollo e Nóbrega (2011), ao se referirem a uma conferência de Umberto Eco, destacam a ideia de que numa biblioteca encontramos "livros para ler" e "livros para consultar", seja no suporte do livro impresso, com sua leitura mais linear, seja no ambiente virtual, com seus hipertextos e outros recursos que influenciam os modos de leitura dos leitores e as formas de apreendê-las. Os "livros para ler" seriam aqueles que demandam leituras mais atentas e que, para o 
leitor construir sentidos, precisariam ser lidos preferencialmente do começo ao fim, como um romance, um conto, um poema. Já os "livros para consultar" seriam os que buscamos com o intuito de localizar diferentes informações sobre um determinado assunto e não necessariamente precisariam ser lidos até o final. Embora esta classificação possa dar algumas pistas para se organizar uma biblioteca escolar, cabe ressaltar que ler ou consultar são ações relacionadas não apenas ao gênero ou à proposta interlocutiva do livro, mas às intenções do leitor. Um livro de poemas, por exemplo, pode ser consultado para se retirar uma epígrafe para iniciar a escrita de um outro texto. Por sua vez, uma consulta escolar pode exigir dos estudantes uma leitura intensiva, com idas e vindas, ainda que em parte de uma obra informativa. Assim, de um modo ou de outro, para que o ato de ler se torne significativo, como ressalta Britto (2011, p. 21), a leitura exige que o leitor incorpore um conjunto de atitudes, tais como: "saber compreender o conteúdo de um texto em seu sentido, compará-lo com outros elementos, realizar associações, tirar conclusões etc." Livros e leituras se articulam, para Chartier (1996), o livro se realiza nas práticas de leitura que deles se apoderam. Portanto, as escolhas para a aquisição e composição dos acervos de uma biblioteca escolar são um primeiro e importante movimento, mas, para ela construir sua identidade, faz-se também necessário constituí-la como um espaço de promoção e acesso à leitura e à ampliação cultural. Sem acervo, não há biblioteca, e os acervos de uma biblioteca dizem para que e para quem se destina aquele lugar, e sem proposta de leitura, a biblioteca torna-se um depósito de livros como meros objetos.

Consideramos que bibliotecas de escolas públicas municipais que se pretendem democráticas precisam ter acervos de qualidade, com obras que dificilmente poderiam ser adquiridas por grande parte da população, e também precisam abrir possibilidades de leitura deste acervo. Não é nossa intenção discutir qualidade dos acervos neste artigo, mas no âmbito da literatura infantil, categoria que obteve $80 \%$ das respostas como prioridade de compra das secretarias, concebemos qualidade tomando como ponto de partida a articulação entre as três artes: i) da palavra - que inclui a literariedade; ii) das artes visuais ilustração; e iii) do design gráfico - que engloba o projeto gráficoeditorial da obra. Articulação compreendida, de acordo com Bakhtin (2003), como interdiscursividade entre as linguagens verbal e visual, 
numa estreita e indissociável relação entre forma e conteúdo. Interdiscursividade que inclui a presença das diferentes vozes que compõem os textos verbal e visual. Nesta perspectiva dialógica marcada na própria obra, Belmiro (2012, p. 127) ajuda a pensar a leitura em relação à superação da dicotomia ver versus ler, "adicionando ao ver o estatuto de ler alguma coisa, e ao ler, as condições de poder ver alguma coisa. O que nos une é o dizer e isso solicita uma discursividade que recupera a presença dos interlocutores e seus atos de fala". Assim, o livro de literatura infantil considerado de qualidade seria aquele em que as diferentes vozes em interlocução se abrem discursivamente ao leitor, que responde ao produzir sentido e se desloca afetado pela experiência estética.

À constituição do acervo juntam-se outras ações, tais como: sua classificação e organização, a ordenação do próprio espaço físico e as práticas de dinamização da leitura a partir dos acervos existentes e empreendidas pelos profissionais que ali atuam. Portanto, numa biblioteca escolar toda materialidade do espaço e dos objetos se soma às subjetividades dos discursos que ali circulam. A estética e a ética entendidas com Bakhtin (2003) de forma articulada, se traduzem nos espaços dialógicos instituídos nas interlocuções, nas réplicas das respostas, na responsividade perante o outro. Nas práticas de leitura que têm a linguagem na sua dimensão expressiva na qual ciência, arte e vida se articulam na unidade de sentido e significados partilhados.

\section{Onde ficam os livros de literatura nas escolas fluminenses?}

São muitos os acervos que adentram a escola em seus diferentes espaços de leitura. A sala de leitura ou biblioteca é um deles, mas nem sempre ela representa o espaço priorizado para a guarda de livros e outros acervos. Por isso, o questionário trouxe uma pergunta especialmente direcionada à guarda e circulação dos livros literários: onde ficam os livros de literatura infantil na maioria das escolas municipais? Esta questão foi dirigida a cada um dos segmentos creche, pré-escola e ensino fundamental - e apresentou a possibilidade da marcação de mais de uma resposta. 
GRÁFICO 3 - Lugares onde ficam os livros de literatura nas escolas municipais do Estado do Rio de Janeiro, por segmento - Rio de Janeiro (2015)

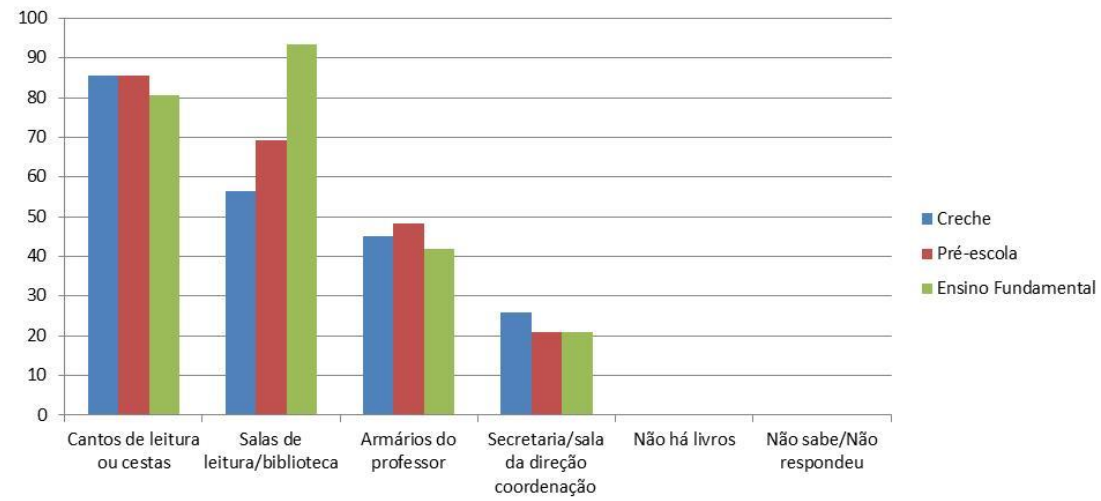

Fonte: Microdados da pesquisa "Infância, Linguagem e Escola: a Leitura Literária em Questão". Rio de Janeiro: UFRJ, 2015.

De acordo com os 62 municípios respondentes, a maior parte do acervo das creches $(85,48 \%)$ encontra-se disponibilizado em cestas ou cantos de leitura. Nas creches, os livros de literatura também circulam pelas estantes e armários dos diretores e coordenadores $(25,81 \%)$ e dos professores $(45,16 \%)$. É interessante observar que pouco mais da metade dos municípios respondentes $(56,45 \%)$ indicam que a maior parte de seu acervo está reunida em salas de leitura e bibliotecas. Uma proporção que aponta uma presença menor de bibliotecas nas creches.

As respostas referentes à pré-escola ficaram mais próximas das da creche, com notória presença de livros em cantos e cestas $(85,48 \%)$, mas também em espaços de guarda nas salas de atividades, em armários e estantes dos professores $(48,39 \%)$ e em armários e estantes das salas de direção/coordenação $(20,97 \%)$. Porém, mais distante do percentual que encontramos nas creches, o número de títulos reunidos em salas de leitura e biblioteca nas pré-escolas chega a $69,81 \%$ das respostas.

De forma diferente aos segmentos anteriores, os livros de literatura no ensino fundamental ficam reunidos em grande número nas bibliotecas e salas de leitura $(93,55 \%)$. Mas o acervo literário também circula por cestas e cantos de leitura (80,65\%). Há também títulos reunidos junto à coordenação/direção $(21,97 \%)$ e aos professores $(45,16 \%)$.

Considerando as respostas que apontam a guarda de livros em cestas e caixas nas creches e pré-escolas, principalmente, mas também 
em número expressivo no ensino fundamental, podemos nos aproximar das reflexões de Perrotti (2004) sobre as estações de leitura de uma escola entendidas como lugares de guarda de acervo: estações fixas (bibliotecas, armários, estantes) ou estações circulantes (caixas, cestos, baús). Assim, independentemente das estações de leitura serem organizadas como instalações permanentes ou temporárias, há uma questão a se pensar: como os leitores têm acesso aos livros? De forma livre e direta ou com diferentes restrições? Especialmente com relação às estações de leitura fixas, Corsino, Branco e Vilela (2014) ressaltam duas categorias para as estações fixas: aquelas que permitem o livre acesso dos leitores aos livros e as que são de acesso restrito. Observamos nas respostas analisadas que, em todos os segmentos, armários e estantes nas salas de coordenação/direção e também os armários dos professores aparecem como lugares de guarda de livros para muitos municípios respondentes. A partir destas respostas inferimos que grande parte das estações fixas podem se configurar como de pouca ou nenhuma acessibilidade das crianças.

A questão da inacessibilidade do acervo remete à própria história da biblioteca em diferentes sociedades. Para Nóbrega (2002), o caráter de inacessibilidade das bibliotecas foi se modificando socialmente e o espaço foi se abrindo para novas experiências e funções: de lugar especialmente de guarda às práticas que pretenderam extrapolar a ideia de armazém de livros, a biblioteca procurou se constituir como espaço social e democrático, onde poderia haver circulação de conhecimento, discussão e criação. Nesse percurso, diferentes faces para a biblioteca foram reveladas e, sem que uma suplantasse as outras, chegou-se também à sua face educadora. Qual o lugar da biblioteca escolar ou sala de leitura na educação de crianças? Que diferentes faces dos espaços de guarda e circulação de livros dos municípios fluminenses respondentes fizeram-se presentes? Foi possível observar que há oferta de livros em todos os municípios respondentes, o que indica uma preocupação em democratizar e socializar esses bens culturais. No entanto, esse acervo nem sempre parece acessível a todos os leitores.

\section{A classificação e organização do acervo}

Como a maioria das escolas municipais do Estado do Rio de Janeiro que responderam ao questionário organiza seus acervos? Esta questão também 
foi dirigida a cada um dos segmentos - creche, pré-escola e ensino fundamental -, com a possibilidade da marcação de mais de uma resposta.

A classificação do acervo e sua organização no espaço da biblioteca ou sala de leitura é um assunto que preocupa muitas escolas que dispõem desse espaço de leitura ou desejam implementá-lo. Pesquisadores das áreas da educação e da ciência da informação vêm se debruçando sobre o tema, sem, contudo, chegarem a uma definição sobre como esse trabalho deve ser concretizado. Em pesquisa realizada em escolas e creches do município do Rio de Janeiro, Corsino, Branco e Vilela (2014), ao analisarem bibliotecas infantis das escolas que compunham o corpus da pesquisa, chegaram à conclusão de que, no que tange à organização dos acervos, não havia uma padronização. Com Benjamin (1994) entendemos que, numa biblioteca, a ordem está sempre por um fio, pois, a cada novo livro que se adquire, novas arrumações se impõem, portanto, está sempre prestes a se alterar. Entretanto, sem perder o "inconfundível" de cada biblioteca, perguntamos se ter alguma padronização não poderia dar maior acessibilidade aos livros. O que dizem então as respostas do questionário a respeito das formas de classificação e organização dos acervos nos espaços de salas de leitura ou bibliotecas das escolas das redes municipais de ensino de municípios fluminenses?

GRÁFICO 4 - Modos de classificação e organização dos acervos de bibliotecas das escolas públicas municipais, por segmento -Estado do Rio de Janeiro (2015)

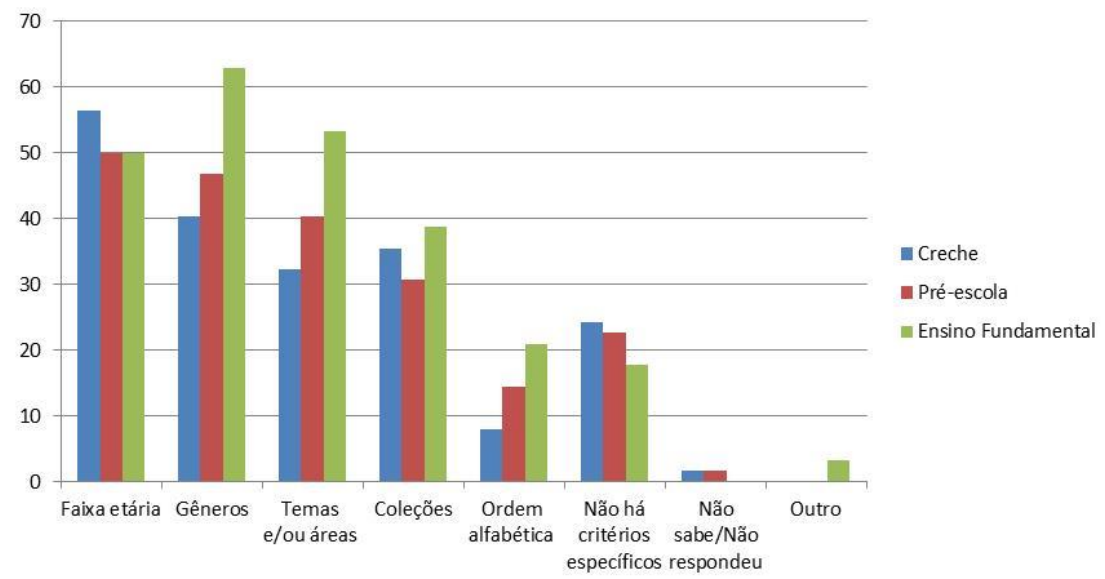

Fonte: Microdados da pesquisa "Infância, Linguagem e Escola: a Leitura Literária em Questão". Rio de Janeiro: UFRJ, 2015. 
O questionário ofereceu como opções de respostas diferentes modos de classificação e organização de acervos: faixa etária, gêneros, temas e/ou áreas de conhecimento, coleções, ordem alfabética e ausência de critérios, sendo que mais de uma resposta poderia ser assinalada. Assim, como mostra o gráfico, não houve o predomínio de um único tipo de classificação e organização. Nos três segmentos, as respostas dividiram-se principalmente entre as opções "faixa etária", "gênero", "temas e/ou áreas do conhecimento" e "coleções", com percentuais variando entre $30 \%$ e $65 \%$. Quanto à organização do acervo por "faixa etária" (56,45\% na creche, 50\% na pré-escola e $50 \%$ no ensino fundamental), o resultado de $50 \%$ em todos os segmentos evidencia que este é um critério de organização comum das bibliotecas ou salas de leitura das escolas municipais de educação infantil e anos iniciais do ensino fundamental de municípios fluminenses. Como o acervo das bibliotecas escolares é constituído, principalmente, por obras literárias, indagamos: qual a concepção de literatura infantil subjacente a este critério de organização dos acervos? Como encaixar obras literárias, entendidas em sua dimensão artística, à faixa etária? Em relação à classificação por gênero, há um percentual maior de respostas quando ele se refere à organização das bibliotecas que atendem ao ensino fundamental. Este critério apontaria para o fato de que os estudantes deste segmento já estariam familiarizados com os diferentes gêneros literários, podendo reconhecer suas diferenças e fazer escolhas? Em relação ao tema, destaca-se a organização por esta categoria nas bibliotecas das pré-escolas. Este critério foi observado nas escolas por meio de pesquisa qualitativa (Corsino, 2014), que evidenciou uma não discriminação entre obras de literatura e informativas, o que acabava por reduzir a literatura ao ensino de conteúdos informativos como animais, plantas, meios de transporte, cores, entre outros. A opção por dividir e organizar livros por coleções, embora não tenha sido preponderante, parece seguir uma tendência que se encontra em catálogos de diferentes editoras que se dedicam à literatura infantil e juvenil. É uma escolha que, diferentemente da que aborda os gêneros e os temas ou áreas de conhecimento, não dialoga diretamente com questões cognitivas ou que fazem parte de conteúdos do currículo escolar.

Além das quatro opções de respostas mais assinaladas pelos respondentes, encontramos um dado também interessante, quando se trata da organização por ordem alfabética - creche $(8,06 \%)$, pré-escola $(14,52 \%)$ e ensino fundamental $(20,97 \%)$ - parecendo apontar para o fato 
de que no ensino fundamental as crianças já sabem ler e assim reconheceriam uma classificação e organização de acervo feita por ordem alfabética dos sobrenomes dos autores. Também foi assinalada a opção de resposta "não há critérios". Nos três segmentos, ela apresenta percentuais que, embora não sejam altos, evidenciam que há um grupo de municípios que não está preocupado com a organização e legibilidade dos espaços onde ficam os livros: creche $(24,16 \%)$, pré-escola $(22,58 \%)$ e ensino fundamental $(17,74 \%)$.

Classificar, organizar e disponibilizar o acervo de uma biblioteca ou sala de leitura tem sido uma preocupação para diferentes campos do conhecimento que se dedicam a questões relacionadas à formação de leitores: a forma como se dispõe os acervos no espaço, comunicando e revelando aos leitores as variadas possibilidades de leitura, pode ser compreendida como uma das primeiras ações mediadoras quando se trata de um espaço de livros. De acordo com Travassos (2010, p. 70), "a comunicação clara do espaço, aliada às atividades de educação do usuário para seu conhecimento e uso, colabora para a autonomia do leitor dentro da biblioteca, além de mostrar a variedade de leituras que o espaço comporta". No entanto, o debate sobre a classificação e a organização do acervo não se esgota na afirmativa sobre sua importância como elemento mediador da leitura. A classificação e organização do acervo das bibliotecas escolares está em pauta, e há diferentes posicionamentos no campo da ciência da informação sobre essa questão. De acordo com Campello (2010, p.140), para uma biblioteca se organizar e permitir fácil acesso ao seu acervo, os conhecimentos técnicos desse campo são fundamentais:

é importante saber que as técnicas utilizadas por bibliotecários na organização da coleção são geralmente padronizadas, colocando a biblioteca em condições de se integrar eventualmente em redes de informação. Essa padronização também é necessária para permitir que os estudantes se familiarizem com uma organização que é comum à maioria das bibliotecas.

Vianna (2002) compreende que muitas bibliotecas escolares optam por utilizar formas simplificadas na organização de seus acervos, fazendo uso de cores ou criando outros tipos de agrupamentos e sinalizações. Porém, indo ao encontro dos posicionamentos de Campello (2010), Vianna (2002, p. 43) pondera que, se por um lado, esse procedimento pode parecer prático, por outro, "pode impedir que alunos conheçam formas 
consolidadas de organização de bibliotecas com as quais certamente vão se deparar mais tarde, em sua vida escolar".

Mas nem todos os estudiosos deste campo apresentam os mesmos olhares sobre a questão. De acordo com Ramos et al. (2011, p. 58-59), por exemplo, a organização dos acervos no espaço da biblioteca escolar pode ser diferente, uma vez que estas se diferenciam, em muitos aspectos, de outros tipos de bibliotecas:

O profissional que atua em BEs [bibliotecas escolares], independente de sua formação, é, com efeito, um agente cultural. Sua função se difere dos demais nichos de atuação biblioteconômico e a organização do material em BEs não foge desse padrão, pois é preciso adaptar essa organização de acordo com a demanda da comunidade a qual está inserida.

Para os autores, a biblioteca escolar, cujo público atingido é formado principalmente por crianças e adolescentes, deveria proporcionar fácil acesso ao material contido nela, inclusive explorando a necessidade pelo lúdico de parte desse público. Neste caso, os símbolos da Classificação Decimal de Dewey (CDD) e da Classificação Decimal Universal (CDU), presentes na classificação dos acervos da maioria das bibliotecas não escolares, não cumpririam o papel desejado de proporcionar autonomia aos leitores para encontrarem nas estantes aquilo que desejam.

Com relação a classificar ou não os livros de uma biblioteca escolar a partir dos sistemas CDU e CDD, Albernaz (2008) ressalta ainda que nem sempre a organização de bibliotecas obedeceu a estes sistemas de classificação decimal, referentes a assuntos padronizados. A autora aposta na ideia de uma desnaturalização de tais convenções para buscar, a partir de problemas concretos, o estabelecimento de princípios próprios, pois "cada biblioteca vem acompanhada de um projeto intelectual, de uma ordenação, de uma 'sintaxe', favorecendo a geração de diálogos, a justaposição de ideias, fatos e informações" (Albernaz, 2008, p. 43). Essa geração de diálogos também pode apresentar-se a partir de organizações de acervo temporárias no espaço da biblioteca. Como ressaltam Corsino, Branco e Vilela (2014), a biblioteca, além de dispor da organização própria, também pode propor composições e organizações de coleções de livros variadas e flexíveis (tipos de textos, temas, autores, gêneros etc.) que podem chamar a atenção dos leitores, constituindo-se em um convite à leitura. 
Classificar e organizar os acervos na biblioteca escolar constitui-se num importante elemento mediador da leitura. Assim, no questionário também foi feita a pergunta: "A Secretaria de Educação elaborou orientações para guarda, preservação, organização e funcionamento das bibliotecas/salas de leitura das escolas municipais?"

GRÁFICO 5 - Percentual de secretarias municipais de educação, por elaboração de orientação para guarda, preservação , organização e funcionamento das bibliotecas de escolas públicas municipais - Estado do Rio de Janeiro (2015)

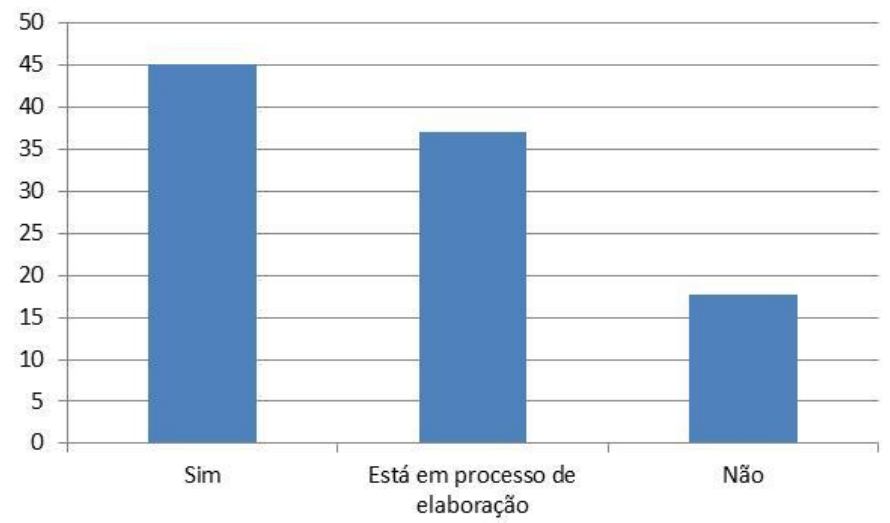

Fonte: Microdados da pesquisa "Infância, Linguagem e Escola: a Leitura Literária em Questão". Rio de Janeiro: UFRJ, 2015.

Conforme mostra o gráfico 5, 45,16\% dos respondentes afirmaram já terem elaborado tais orientações, 37,10\% assinalaram a opção "está em processo de elaboração", e 17,74\% marcaram "não" como resposta. Esta questão ofereceu uma segunda pergunta para os municípios que afirmaram já terem desenvolvido orientações em relação à guarda, preservação e organização dos acervos, solicitando que citassem três orientações que considerassem importantes. Dos 28 municípios que assinalaram a opção afirmativa, 21 citaram por escrito as orientações que realizaram. As respostas se concentraram em maior número nos aspectos relacionados à classificação e à organização dos livros no espaço, mas também foram encontradas respostas sobre orientações mais gerais de atendimento aos alunos, além de orientações vinculadas a regulamentos existentes e cursos. Quanto à classificação e registro do 
acervo, entre outras orientações, oito municípios escreveram tê-las desenvolvido. Destacamos duas respostas:

"Registro do acervo em livro tombo. Critério para organização e classificação do acervo. Carteirinha de sócio e/ou caderno de empréstimo".

“Organização do acervo. Classificação por gênero e cores. Descarte de livros segundo a Lei".

Nas respostas escritas, observa-se a presença de algumas orientações que dialogam com o campo mais técnico da ciência da informação, a exemplo da utilização de livros de tombo para efetuar o registro do acervo, assim como a questão do descarte. Mas também há orientações sobre classificações diferentes, como por gêneros e cores. Se pensarmos no contexto dos 62 municípios respondentes do questionário, ainda são pouco significativas as orientações já existentes que se referem à classificação e ao registro do acervo. Esta situação se repete no que tange a orientações para a organização do acervo no espaço. Das cinco respostas sobre a questão, destacamos três exemplos:

“Organização dos livros/disponibilização dos livros ao alcance dos alunos; atendimento aos alunos, no mínimo, uma aula por semana".

"A organização dos livros dentro da biblioteca é por assunto direcionando o docente à pesquisa".

“Organização de acordo com a faixa etária. Organização por gênero".

Nessas respostas, diferentemente do que se observou em relação à classificação, não há referências a uma organização mais ligada aos aspectos técnicos. As poucas orientações sobre esse aspecto podem apontar para a preocupação de se organizar os livros direcionando-os aos tipos de frequentadores do espaço.

Outro grupo de respostas, envolvendo nove municípios, trata de orientações sobre o funcionamento mais geral da biblioteca, envolvendo o uso que os frequentadores fazem do espaço, como orientações ligadas à atividade de empréstimos, cadastro dos alunos e carteirinhas, conservação do ambiente e dos livros, orientações sobre as funções do responsável. Por fim, há ainda cinco repostas que tratam sobre os 
documentos existentes e cursos para os responsáveis das bibliotecas. Vejamos duas:

“As Salas de Leitura são Regulamentadas pelo Regimento Escolar do Município que define em seus Art. 21 e 22, os objetivos do espaço e a função dos Dinamizadores de Leitura".

“Curso de Formação Continuada para

Professores/Dinamizadores de Sala de Leitura".

A leitura e análise das duas questões do questionário aqui destacadas sobre as formas de classificação do acervo e sua organização nas salas de leitura e bibliotecas, indicam que os municípios vêm dialogando com essas questões, porém por caminhos diferentes: cada município desenvolve suas ações a partir de compreensões e critérios diversos. As preocupações sobre como os acervos devem ou não estar nos espaços das bibliotecas apontam mais fortemente para estratégias que buscam aproximar os leitores dos acervos, no intuito de socializar os bens culturais por elas guardados.

\section{Biblioteca/sala de leitura: de espaço a lugar}

Quando um espaço físico, como uma biblioteca, transforma-se em um lugar de encontro? Partilhando da ideia de que "a mediação entre o livro e o leitor começa no ambiente" (Corsino, 2010, p.201), discutiremos como a biblioteca pode transformar-se em lugar de encontro. Para isso, a pesquisa buscou saber: "além de livros, o que mais compõe o acervo das bibliotecas/salas de leitura da maioria das escolas municipais?".

A questão, que permitia assinalar mais de uma resposta, aponta que as bibliotecas/sala de leitura das escolas municipais fluminenses estão preocupadas em oferecer também acesso à informação, pois, além dos livros, são distribuídos e disponibilizados jornais e revistas (83,87\%). Destaca-se também o interesse dos espaços em ampliar o contato com a mídia digital por meio de um acervo que inclui CD $(77,42 \%)$ e DVD $(83,87 \%)$. Por fim, percebemos um investimento para que esses espaços possuam jogos $(90,32 \%)$, fantoches $(87,10 \%)$ e fantasias $(43,55 \%)$. Esses dados provocaram o diálogo com as pesquisas qualitativas produzidas pelo grupo de pesquisa. Traremos a seguir reflexões e proposições que tratam a biblioteca como lugar de relações e interlocuções de diferentes naturezas: de investigação, de leitura em diferentes suportes e de narratividade. 
GRÁFICO 6 - Percentual de tipos de acervos que compõem as bibliotecas/salas de leitura de escolas públicas municipais - Estado do Rio de Janeiro (2015)

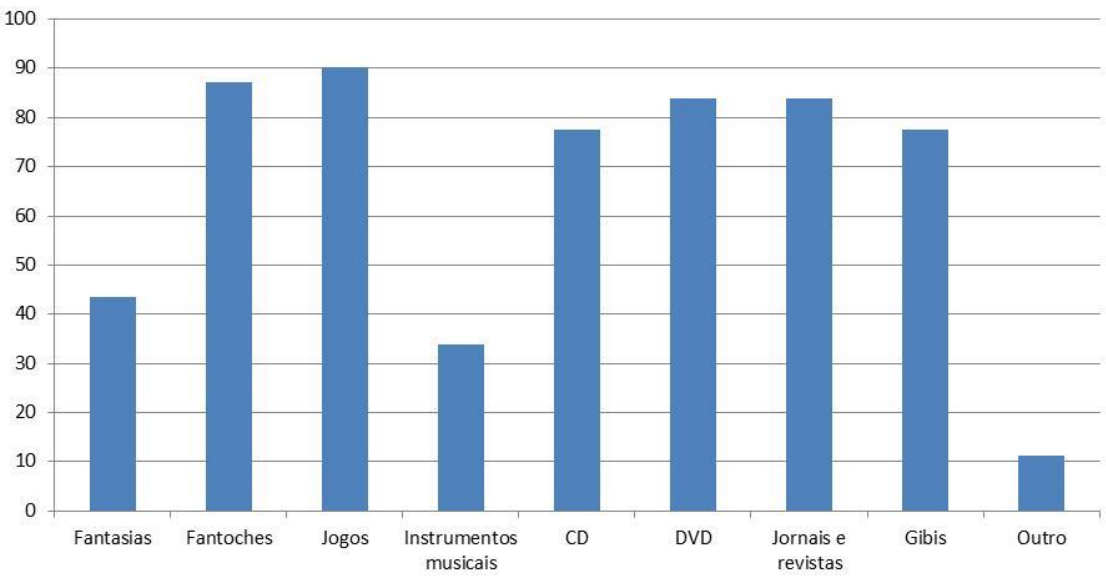

Fonte: Microdados da pesquisa "Infância, Linguagem e Escola: a Leitura Literária em Questão". Rio de Janeiro: UFRJ, 2015.

Os espaços da biblioteca/sala de leitura podem ser potentes ambientes de pesquisa e investigação. Mas, para que seja um lugar de acesso a informações, as bibliotecas necessitam disponibilizar além dos "livros para consultar" (Mollo e Nóbrega, 2011), diferentes suportes para a busca de informação. Campello (2010, p. 131) aponta que "ao reunir livros e outros recursos informacionais, a biblioteca reproduz, de certa maneira, o ambiente informacional da sociedade contemporânea". Para Vieira e Fernandes (2010, p. 110), "o professor da sala de leitura deve trabalhar com informações nos mais diferentes suportes: dicionários, enciclopédias, revistas, sites etc." A biblioteca escolar pode ser um lugar para pesquisas individuais e coletivas que envolvam crianças de todas as idades da comunidade escolar. Campelo (2010) afirma, ainda, que é nos momentos de discussão que os leitores irão aprender a lidar com a vasta quantidade de informações do mundo moderno, conhecendo diversos modos de localizar, selecionar, utilizar e compartilhar o que encontram.

As respostas dos municípios apontam a preocupação em disponibilizar CD e DVD nos espaços de livro e leitura. Embora, estes não sejam a primeira opção de compra, como discutido no item sobre aquisição do acervo, observa-se que há municípios cujas escolas contam 
com esses suportes em suas bibliotecas ou salas de leitura. Ao mesmo tempo que essas mídias podem ser utilizadas como simples entretenimento, podem também desencadear propostas de articulação interessantes entre literatura e música, literatura e cinema, cinema e informação etc. Sons e imagens podem ampliar a relação das crianças com a leitura.

A biblioteca pode ser também lugar de narrativa. A ideia de que os livros possam estar junto a jogos, fantoches e fantasias diz de uma concepção de espaço que entende a leitura enquanto prática criadora, produtora de sentidos. Para Benjamin (1994), a narrativa é uma forma artesanal de comunicação que necessita de tempo para acontecer. Narrar e ouvir histórias têm relação com uma atmosfera que não é cronológica, visto que se constitui de uma temporalidade não mensurável, baseada na intensidade.

Ao refletir sobre o papel do espaço no desenvolvimento das experiências das crianças, Guimarães (2009) contribui para pensarmos as bibliotecas como lugares de narratividade. Suas considerações destacam a importância de se ter nas escolas espaços flexíveis, instigadores e que provoquem e sustentem relações. A ideia de que o espaço planejado pelo arquiteto é distinto do espaço experimentado pelas crianças considera uma diferença entre os termos espaço e lugar, frequentemente empregados como sinônimos. A autora ressalta que a relação com o tamanho do espaço não se dá apenas pela sua metragem, mas especialmente pelo modo com que ele é habitado. Nesse sentido, entende o espaço como algo projetado e o lugar como algo construído a partir das relações. Assim, a biblioteca/sala de leitura se constituem como lugares de variadas interlocuções provocadas pelas leituras individuais e coletivas, pelos jogos de linguagem, pelas narrativas, pelas produções de sentidos e significados, pelas invenções e criações.

As bibliotecas infantis podem ser convidativas: tapetes, almofadas, estantes e mesas são elementos bem-vindos. O espaço físico pode potencializar a imaginação das crianças, e isso só é possível em ambientes preparados intencionalmente. Apesar de importante, não basta apenas um ambiente aconchegante para garantir a interação entre as crianças. O espaço relacional é mais que isso, é também a disponibilidade de tempo para as interlocuções acontecerem. A organização e a disposição dos livros e objetos são importantes para favorecer a expressividade das crianças. Para que os espaços sejam 
instigadores e convidem à ação, à expressividade, à escuta, aos deslocamentos - físicos e imaginativos - das crianças, à imaginação e à narratividade, é importante que o professor atue quase como um cenógrafo, disponibilizando elementos que possam mobilizar o potencial sensível e construtivo das crianças. Cores, luzes, superfícies, formas e texturas ampliam essas possibilidades de interação e criação.

\section{Considerações finais}

Este texto teve como objetivo analisar parte dos resultados obtidos com um questionário endereçado às secretarias municipais de educação do Estado do Rio de Janeiro visando traçar um panorama das políticas educacionais voltadas para o livro e a leitura. Neste artigo discutimos aquisição, organização e catalogação do acervo que compõe as bibliotecas escolares, bem como a concepção destes espaços de leitura.

Em relação à aquisição do acervo, embora as doações sejam ainda citadas pelas secretarias como forma de composição de acervos de bibliotecas escolares, grande parte dos municípios destacou que seu acervo é constituído a partir de compras realizadas pelas prefeituras ou secretarias ou, ainda, a partir de verbas disponibilizadas para as escolas por estas mesmas instâncias. Nesse sentido, foi possível observar a importância das verbas públicas municipais para a aquisição e composição do acervo das escolas municipais do Estado do Rio de Janeiro e o compromisso políticopedagógico de coordenadores e professores responsáveis pelas compras. Em relação às compras realizadas, as repostas indicam que os livros de literatura infantil são prioridades, seguidos pelos livros informativos. A opção pelos suportes impressos também aparece como forte tendência, visto que há pouco investimento dos municípios na aquisição de jogos e programas para computador e e-books literários ou informativos.

Onde ficam os livros na escola? Essa questão apontou embate entre os diferentes segmentos. Na educação infantil, a maior parte do acervo é disponibilizada em cestas e cantos de leitura, sendo as bibliotecas ou salas de leitura uma segunda opção para a reunião do acervo em creches e pré-escolas. Já no ensino fundamental, esses dados se invertem e as bibliotecas e salas de leitura aparecem como principal espaço de reunião de livros, seguidos pelas cestas e cantos de leitura. Respostas que reafirmam que as bibliotecas e salas de leitura estão presentes em maior número em escolas de ensino fundamental. 
As respostas dos municípios em relação à organização e à classificação do acervo no espaço da biblioteca ou da sala de leitura apontaram que as creches e pré-escolas tendem a organizar seu acervo priorizando a faixa etária dos leitores, embora exista uma tendência de ampliação na pré-escola para a organização por gêneros. Já no ensino fundamental, essa organização se diversifica entre gêneros e temas e/ou áreas de conhecimento. A organização dos títulos em ordem alfabética também desponta neste segmento. A falta de critérios para a organização do acervo, apesar de não ser expressiva, aponta para a necessidade de ampliação das discussões sobre disposição e classificação do acervo, principalmente quando se trata de bibliotecas infantis. Ainda neste viés, buscamos observar se há orientações para guarda, preservação, organização e funcionamento das bibliotecas e salas de leitura das escolas municipais pelas secretarias de educação. As respostas afirmam que a maior parte dos municípios já elaboraram tais orientações ou declaram estar em processo de elaboração.

Além de livros, o que mais compõe o acervo das bibliotecas e salas de leitura da maioria das escolas municipais? Essa pergunta contribuiu para entender as diferentes faces da biblioteca. As respostas apontaram para a preocupação em disponibilizar jornais e revistas, em ampliar o contato com a mídia digital através de um acervo que inclui CD/DVD e, por fim, em oferecer jogos, fantoches e fantasias. Escolhas que afirmam que biblioteca é espaço de construção de narrativas, mas também de investigação e de encontro com diferentes suportes e linguagens.

O questionário evidenciou um importante movimento das secretarias municipais de educação de municípios fluminenses em desenvolver ações e projetos relacionados à aquisição de livros para as escolas. Na perspectiva de Candido (2011), que concebe a literatura como direito, cabem pesquisas qualitativas para investigar como estes livros têm chegado às crianças, quais as leituras que deles se apoderam nas escolas fluminenses e onde se encontram o inescrutável e o inconfundível das bibliotecas das escolas públicas municipais.

\section{Referências}

ALBERNAZ, Maria Beatriz (2008). Sete desafios da biblioteca escolar. In: BRASIL. Ministério da Cultura. Fundação Biblioteca Nacional. Programa 
Nacional de Incentivo à Leitura (Proler). Brasília: MEC, p. 35-48. (Coleção Cursos da Casa de Leitura)

BAKHTIN, Mikhail (2003). Estética da criação verbal. Tradução de Paulo Bezerra. São Paulo: Martins Fontes.

BELMIRO, Celia Abicalil. Entre modos de ver e modos de ler, o dizer. Educação em Revista, Belo Horizonte, v. 4, p. 105-131, 2012.

BENJAMIN, Walter (1994). Obras escolhidas I: magia e técnica, arte e política. São Paulo: Brasiliense.

BRITTO, Luis Percival (2011). O papel da biblioteca na formação do leitor. Boletim Salto para o Futuro - Biblioteca escolar: que espaço é esse?, Rio de Janeiro, ano 21 , n. 14, p.18-25.

CAMPELLO, Bernadete (2010). A biblioteca escolar como espaço de aprendizagem. In: PAIVA, Aparecida; MACIEL, Francisca; COSSON, Rildo (Coord.). Literatura: ensino fundamental. Brasília: MEC, SEB, p. 127-142. (Coleção Explorando o Ensino)

CANDIDO, Antonio (2011). O direito à literatura. In: CANDIDO, Antonio. Vários escritos. Rio de Janeiro: Ouro sobre Azul.

CHARTIER, Roger (1994). Do códex à tela: as trajetórias do escrito. In: CHARTIER, Roger. A ordem dos livros. Brasília: Editora da UnB.

CORSINO, Patrícia (2010). Literatura na educação infantil: possibilidades e ampliações. In: PAIVA, Aparecida; MACIEL, Francisca; COSSON, Rildo (Coord.). Literatura: ensino fundamental. Brasília: MEC, SEB, p. 127-142. (Coleção Explorando o Ensino)

CORSINO, Patrícia; BRANCO, Jordanna; VILELA, Rafaela (2014). Reflexões sobre espaços e lugares de livro e leitura em escolas de educação infantil e ensino fundamental I. In: CORSINO, Patrícia (Org.). Travessias da literatura na escola. Rio de Janeiro: 7 Letras, p. 241-256.

CORSINO, Patrícia (Org.) (2014). Travessias da literatura na escola. Rio de Janeiro: 7 Letras.

GUIMARÃES, Daniela (2009). Educação infantil: espaços e experiências. In: CORSINO, Patrícia (Org.). Educação infantil: cotidiano e políticas. Campinas: Autores Associados, p. 93-104.

MOLLO, Glaucia; NOBREGA, Maria José (2011). Introdução. Boletim Salto para o Futuro - Biblioteca escolar: que espaço é esse?, Rio de Janeiro, ano 21, n.14, p.4-11. 
NOBREGA, Nanci (2002). De livros e bibliotecas como memória do mundo: dinamização de acervos. In: YUNES, Eliana. Pensar a leitura: complexidades. São Paulo: Loyola.

PAIVA, Aparecida (2012). Políticas públicas de leitura: pesquisas em rede. In: PAIVA, Aparecida (Org.). Literatura fora da caixa: o PNBE na escola Distribuição, circulação e leitura. São Paulo: Editora UNESP.

PERROTTI, Edmir (2004). Lugares da leitura: a escola como espaço de leitura. Boletim Salto para o Futuro - Espaços de leitura, Rio de Janeiro, p. 8-18.

RAMOS, Clériston et al. (2011). Imagem e percepção: alternativa aplicada na classificação da literatura infantojunvenil de uma biblioteca escola. Perspectivas em Ciências da Informação, v. 16, n. 4, p.55-72.

TRAVASSOS, Sonia (2010). Biblioteca escolar: muito além de estantes arrumadas. In: BRASIL. Ministério da Cultura. Fundação Biblioteca Nacional. Biblioteca e mediação da leitura. Brasília: MEC, 2008. p. 35-48. (Coleção Cursos da Casa de Leitura)

TRAVASSOS, Sonia (2013). Lobato, infância e leitura: a obra infantil de Monteiro Lobato em diálogo com crianças na escola da atualidade. $238 \mathrm{f}$. Dissertação (Mestrado em Educação) - Universidade Federal do Rio de Janeiro, Rio de Janeiro.

VIANNA, Márcia (2002). A organização da coleção. In: CAMPELLO, Bernadete et al. A biblioteca escolar: temas para uma prática pedagógica. Belo Horizonte: Autêntica.

VIEIRA, Adriana; FERNANDES, Célia (2010). O acervo das bibliotecas escolares e suas possibilidades. In: PAIVA, Aparecida; MACIEL, Francisca; COSSON, Rildo (Coord.). Literatura: ensino fundamental. Brasília: MEC, SEB, p. 127-142. (Coleção Explorando o Ensino)

Recebido em fevereiro de 2016.

Aprovado em agosto de 2016.

\section{resumo/abstract/resumen}

\section{Reflexões sobre políticas de livro e leitura de secretarias municipais de educação do Estado do Rio de Janeiro}

Patrícia Corsino

Rafaela Vilela 


\section{Sônia Travassos}

Este artigo se propõe a analisar questões referentes à composição de acervos e à organização de bibliotecas de escolas das redes públicas municipais de ensino dos municípios do Estado do Rio de Janeiro. As análises apresentadas fazem parte dos resultados da pesquisa "Infância, linguagem e escola: a leitura literária em questão", desenvolvida no PPGE-UFRJ, obtidos a partir das respostas ao questionário distribuído a 92 secretarias municipais de educação do Estado do Rio de Janeiro e respondido por 62 (67\%). Para sustentar as análises sobre constituição de acervo, buscou-se interlocução com Britto (2011), Chartier (1996), Corsino (2010) e Paiva (2012). E para tecer considerações sobre biblioteca, o trabalho ancorou-se nos estudos de Campello (2010), Mollo e Nobrega (2010) e Perrotti (2004). Alguns resultados se destacaram: o importante lugar ocupado pelas secretarias municipais de educação na compra de acervos para as escolas públicas municipais, desde a creche; a opção pela compra de impressos e por livros de literatura infantil; e a biblioteca como espaço de livro e leitura prioritariamente nas escolas de ensino fundamental.

Palavras-chave: politicas de livro e leitura, literatura na rede pública de ensino, leitura literária.

\section{Reflections on book and reading policies of the municipal secretariats of education of the State of Rio de Janeiro}

Patrícia Corsino

Rafaela Vilela

Sônia Travassos

This article aims to analyze issues related to the composition of collections and the organization of school libraries in the municipal educational networks in the municipalities of the State of Rio de Janeiro. The analysis presented are part of the research about "Childhood, language and school: a literary reading in question", developed in PPGE-UFRJ, whose results came about through from the responses to the questionnaire distributed to the 92 municipal departments of education of the State of Rio de Janeiro and that had a response rate of $62(67 \%)$. To support the analysis about the establishment of these library collections, this essay dialogues with the work of Britto (2011), Chartier (1996), Corsino (2010) and Paiva (2012). In order to offer a reflection about these libraries, we anchor our work in studies by Campello (2010), Mollo and Nobrega (2010) and Perrotti (2004). Some results stood out: the important place occupied by the municipal departments of education in buying collections for public schools, beginning at kindergarten level; the choice of printed materials and children's literature books; and the configuration of the library 
as a place for books and the important role that reading has in elementary education.

Keywords: book and reading policies, literature in public schools, literary Reading.

\section{Reflexiones sobre las políticas de libro y lectura de secretarías municipales de educación del Estado de Río de Janeiro}

Patrícia Corsino

Rafaela Vilela

Sônia Travassos

Este artículo tiene como objetivo analizar los temas relacionados con la composición de las colecciones y la organización de las bibliotecas de las escuelas en las redes educativas municipales en los municipios del Estado de Río de Janeiro. Los análisis presentados son parte de los resultados de la investigación "Infancia, lenguaje y escuela: la lectura literaria en cuestión", desarrollado en PPGE-UFRJ, obtenidos a partir de las respuestas al cuestionario distribuido a 92 secretarías municipales de educación del Estado de Río de Janeiro y respondido por 62 de ellas (67\%). Para apoyar los análisis sobre constitución del acervo documental busco dialogar con Britto (2011), Chartier (1996), Corsino (2010) y Paiva (2012). Para hacer consideraciones acerca de la biblioteca, el trabajo se basa en los estudios de Campello (2010), Mollo y Nobrega (2010) y Perrotti (2004). Algunos resultados que se destacan son: el importante lugar ocupado por los departamentos de educación municipal en la compra de colecciones a las escuelas públicas, desde la guardería; la elección de compra de materiales impresos y de libros de literatura infantil; y finalmente la biblioteca como el espacio del libro y la lectura prioritariamente en las escuelas primarias.

Palabras clave: políticas de libro y lectura, literatura en escuelas públicas, lectura literaria. 